Original Research Article

\title{
Antibiotic sensitivity profile and resistance of microorganisms isolated from south Indian population, a hospital based study at Velappanchavady, Chennai, India
}

\author{
Brethis C. S. ${ }^{1 *}$, Mahender G. ${ }^{2}$, Thamizharasan S. ${ }^{1}$, Suresh Kumar K. ${ }^{3}$, Sudharson T. ${ }^{3}$
}

\begin{abstract}
${ }^{1}$ Department of Pharmacology, A.C.S Medical College and Hospital, Velappanchavadi, Chennai, Tamil Nadu, India ${ }^{2}$ Department of Forensic Medicine and Toxicology, District Hospital Gajwel, Telangana, India ${ }^{3}$ Department of Forensic Medicine and Toxicology, A.C.S Medical College and Hospital, Velappanchavadi, Chennai, Tamil Nadu, India

Received: 14 April 2019 Accepted: 19 April 2019

*Correspondence to:

Dr. Brethis C. S.,

Email: csbrethis@yahoo.com

Copyright: (C) the author(s), publisher and licensee Medip Academy. This is an openaccess article distributed under the terms of the Creative Commons Attribution NonCommercial License, which permits unrestricted noncommercial use, distribution, and reproduction in any medium, provided the original work is properly cited.
\end{abstract}

\begin{abstract}
Background: Increasing rates of antibiotic drug resistance has been noted in recent times and this adversely affects the prognosis and outcomes of patients. There is a greater need for local resistance prevalence data in order to guide empirical prescription and to identify areas in which medical need for newer antimicrobial agents is greater.

Methods: A prospective hospital based observational study was carried out to determine antibiotic sensitivity profile and resistance pattern of microorganisms. Samples were collected from urinary tract infections, while cultures from blood stream infections, sputum samples and Serology. Antibiotic susceptibility was determined by the standard disc diffusion method. Data interpretation was based on CLSI, 2017 guidelines for antimicrobial susceptibility testing.

Results: The predominant isolates from the samples were, Staphylococcus aureus (16.7\%) 67, K. pneumoniae (11.5\%) 46, E. coli (29.4\%) 118, P. aeruginosa (6\%) 24. Escherichia coli, the most common causative organism showed high resistance to commonly used drugs such as Ampicillin (60.1\%) 71, Amoxicillin (53.4\%) 63, Amoxicillin-clavulanic acid (44.1\%) 52 and Nalidixic acid $(53.4 \%)$ 63. E. coli was found to be most sensitive to Amikacin (51.7\%) 61, Piperacillin (69.5\%) 82, Norfloxacin (61.9\%) 73, Meropenem (76.3\%) 90 and Imipenem $(68.6 \%) 81$. Klebsiella was most sensitive to $30(65.2 \%)$ ofloxacin, 31 $(67.4 \%)$ ciprofloxacin followed by $24(52.2 \%)$ ceftriaxone and least sensitive to 7 (15.2\%) Amoxicillin and 12 (26.1\%) Ampicillin.

Conclusions: Among commonly used antibiotics resistance to Penicillins (Ampicillin, Amoxicillin) was highest. Resistance to Fluoroquinolones (Ciprofloxacin) was seen in majority of the patients. Among broad spectrum antibiotics Imipenem, Meropenem resistance was seen in lesser proportion of the patients.
\end{abstract}

Keywords: Antibiotic sensitivity, Microorganisms, Resistance

\section{INTRODUCTION}

There is an increase in antibiotic resistance and a decline in new drug development. The primary reasons are widespread misuse of antibiotics, non-human antibiotic use, poor quality of drugs, inadequate surveillance, poor healthcare standard, malnutrition, chronic and repeated infection, unaffordability of more effective and costly drugs .According to a 2014 report by World Health Organization (WHO) on global surveillance of 
antimicrobial resistance, significant gaps in surveillance prevail, along with a lack of standards for methodology, data sharing and coordination. The additional problems are irrational antibiotic prescription by the physicians, habit of self-medication among patients, and indiscriminate use of antibiotics in agriculture and farming in different parts of the country.

To identify the present rate of resistance shown by the clinically significant pathogens, this study was conducted. Bloodstream infection is a major cause of morbidity and mortality despite the availability of potent antimicrobial therapy and advances in supportive therapy. Bacteremia due to gram negative bacilli pose serious therapeutic problems because of the increasing incidence of multidrug resistance.

Acute respiratory tract infections, such as bacterial pneumonia and acute exacerbations of chronic bronchitis, account for a considerable proportion of morbidity and antibiotic use. Moreover, these infections result in high mortality rates. ${ }^{1}$ Unfortunately, the three major bacterial respiratory pathogens; Streptococcus pneumoniae, Staphylococcus aureus and H. Influenza have a worldwide increasing prevalence of antibiotic resistance. ${ }^{2-4}$

Gram negative bacteria were resistant to routinely used antibiotics, hence their resistant pat-tern should be considered essential before deciding the empirical treatment. The higher antibiotics should be reserved for multidrug resistant Gram-negative bacteria, whereas Linezolid and Vancomycin should be reserved for drug resistant Gram positive isolates.

The positive blood culture with antibiotic sensitivity of the isolated organism is the best guide to antimicrobial therapy, as resistance to antibiotics is a worldwide problem that causes ineffectiveness of empirical treatment. More so, strict infection control practices combined with judicious use of antibiotic therapy are the main solutions to this problem. However, it will be important to continue the surveillance of changes in trends and identify risk factors, to obtain information for empiric antibiotic therapy and to act rapidly in case of major changes in susceptibility patterns.

The recent misuse and overuse of antibiotics has induced changes in predominant bacterial species and their susceptibility to antibiotics, making it more difficult to treat. The importance of monitoring the progress of such resistance has led to numerous international, regional and national surveillance programmes. However, results from surveillance studies show wide variations in susceptibility rates, both geographically and over time. ${ }^{5}$ Prevalent flora and antimicrobial resistance pattern may vary from region to region depending upon the antibiotic pressure in that locality. ${ }^{6}$ Thus, there is a great need for local resistance prevalence data in order to guide empirical prescription and to identify areas in which medical need for new agents is greater.

\section{METHODS}

A prospective hospital based observational study was carried out to determine antibiotic sensitivity profile and resistance pattern of microorganisms. Samples were collected from urinary tract infection, while cultures from bloodstream infection, sputum samples and Serology.

Samples included sputum, for Gram stain and culture, blood samples for blood cultures and serum sample for serology. The valid sputum originating from the lower respiratory tract was defined as that containing squamous epithelial cell less than 10/high power field and polymorphonucleocytes more than 25/high power field. The organisms were isolated from sputum culture and blood culture. Serology was positive in all of cases. Indian studies showed sputum culture positivity is low in patients. $^{7-9}$ Decreased sputum positivity is due to (a) inabilityof patients to expectorate due to altered sensorium because of severe disease (b) prior administration of antibiotics (c) $10-30 \%$ of patients have non productive cough. Blood cultures are valuable when positive but negative results are more common even in severe pneumonia. Positive blood culture results were observed in only few of patients with pneumonia. ${ }^{10,11}$

Urine samples collected were clean catch midstream urine samples collected into a wide mouthed sterile container and inoculated on MacConkey and Blood Agar media using calibrated platinum loop following standard bacteriological technique and incubated at $37^{\circ} \mathrm{C}$ overnight. Pure bacterial colony counting 100,000 or more was considered as significant and was subjected to identification based on colony characters and biochemical tests. Blood culture was done after collecting the blood with aseptic precautions before starting antibiotics and 2 $\mathrm{ml}$ of blood was added to two bottles containing $25 \mathrm{ml}$ of Brain heart infusion broth (HiMedia, Mumbai, India). Both the bottles were incubated aerobically at $37^{\circ} \mathrm{C}$ for 7 days. Subculture was done on sheep blood agar and MacConkey agar (HiMedia, Mumbai, India) routinely. Subculture was also done in between if visible turbidity appeared. The isolates were identified based on standard bacteriological techniques. ${ }^{12}$ The growth of an organism was considered pathogenic if the same organism was isolated from both broths and contaminated if either the growth was obtained in only one bottle or a mixed growth was obtained.

Antibiotic sensitivity test was performed by disc diffusion method (Kirby-Bauer's technique) using commercially available discs (HiMedia, India) and the results were recorded following the instruction of the manufacturer. Antibiotic susceptibility was determined by the standard disc diffusion method. The antibiotic disks and their concentrations per disk $(\mu \mathrm{g})$ comprised: Ampicillin (10), Cefotaxime (30), Gentamicin (10), Amikacin (30), Ciprofloxacin (5), Vancomycin (30), Piperacillin (100), Meropenem (10), Ceftriaxone (30), Ceftazidime (30), Amoxycillin (30), Erythro-mycin (15), Cefoperazone (75), 
Cefoxitin (30), Colistin (10), Linezolid (30), Cefpodoxime (10). Data interpretation was based on Clinical and Laboratory Standards Institute guidelines for antimicrobial susceptibility testing (CLSI, 2017). Statistical analysis was carried out using the SPSS software (Version 17). Intergroup comparisons were performed with Chi-square test. A p-value of 0.05 or less was considered statistically significant.

\section{RESULTS}

A total of 401 samples positive for pathogenic organisms were collected. The age and sex distribution of patients was, 215 male patients and 186 female patients within the age group of 24 to 45 years. The most common organism isolated from blood culture was Pseudomonas aeruginosa followed by Staphylococcus aureus and Streptococcus pneumoniae and those from the sputum culture were Streptococcus pneumoniae followed by Pseudomonas aeruginosa.

The predominant isolates in patients were, Staphylococcus aureus $(16.7 \%) 67$, K. pneumoniae $(11.5 \%) 46$, E. coli (29.4\%) 118, P. aeruginosa (6\%) 24 (Table 1).

Staphylococcus aureus showed highest resistance to Penicillins like Ampicillin, Amoxicillin and least resistance to Imipenem and Meropenem (Table 2).

Escherichia coli, the most common causative organism of urinary tract infections showed high resistance to commonly used drugs such as Ampicillin (60.1\%) 71, Amoxicillin (53.4\%) 63, Amoxicillin-clavulanic acid (44.1\%) 52 and Nalidixic acid (53.4\%) 63. E. coli was found to be most sensitive to Amikacin (51.7\%) 61, Piperacillin (69.5\%) 82, Norfloxacin (61.9\%) 73, Meropenem (76.3\%) 90 and Imipenem (68.6\%) 81 (Table 3). Gram negative bacterial isolates were more than Gram positive isolates in this study.

Table 1: Pathogens obtained from urine samples, blood culture, Sputum Culture and Serology.

\begin{tabular}{|c|c|c|}
\hline Pathogen & Number & Percentage $(\%)$ \\
\hline E. coli & 118 & 29.4 \\
\hline Klebsiella & 46 & 11.5 \\
\hline Proteus & 23 & 5.7 \\
\hline Staphylococcus Aureus & 67 & 16.7 \\
\hline $\begin{array}{l}\text { Streptococcus } \\
\text { pneumoniae }\end{array}$ & 41 & 10.2 \\
\hline Salmonella typhi & 28 & 7 \\
\hline Enterococcus & 17 & 4.3 \\
\hline Pseudomonas & 24 & 6 \\
\hline Citrobacter & 12 & 3 \\
\hline Acinetobacter & 14 & 3.5 \\
\hline Enterobacter & 11 & 2.7 \\
\hline
\end{tabular}

Klebsiella was most sensitive to $30(65.2 \%)$ ofloxacin, 31 (67.4\%) ciprofloxacin followed by $24(52.2 \%)$ ceftriaxone and least sensitive to $7(15.2 \%)$ Amoxicillin and 12 (26.1\%) Ampicillin (Table 4). Cotrimoxazole was ineffective against many Pseudomonas isolates and isolates of Enterococcus spp. Ciprofloxacin resistance was displayed by isolates of Enterococcus and Pseudomonas. Pseudomonas were sensitive to Meropenem 17(70.8\%), Imipenem $15(62.5 \%)$, Piperacillin $13(54.2 \%)$ and Amikacin $12(50 \%)$ but showed higher degree of resistance to $8(33.3 \%)$ Ciprofloxacin, $6(25 \%)$ Gentamicin, 7 (29.2\%) Cefotaxime and 5 (20.8\%) Ceftriaxone (Table 5).

Table 2: Resistance and sensitivity of Staphylococcus aureus.

\begin{tabular}{|llll|}
\hline Antibiotics & Sensitive & Intermediate & Resistant \\
\hline Amoxicillin & $17(25.4 \%)$ & $12(18 \%)$ & $38(56.6 \%)$ \\
\hline Ampicillin & $18(26.9 \%)$ & $9(13.4 \%)$ & $40(59.7 \%)$ \\
\hline $\begin{array}{l}\text { Amoxicillin- } \\
\text { clavulanicacid }\end{array}$ & $23(34.3 \%)$ & $15(22.4 \%)$ & $29(43.3 \%)$ \\
\hline Ciprofloxacin & $41(61.2 \%)$ & $11(16.4 \%)$ & $15(22.4 \%)$ \\
\hline Amikacin & $28(41.8 \%)$ & $12(17.9 \%)$ & $27(40.3 \%)$ \\
\hline Erythromycin & $19(28.3 \%)$ & $20(29.9 \%)$ & $28(41.8 \%)$ \\
\hline Cotrimoxazole & $22(32.8 \%)$ & $14(20.9 \%)$ & $31(46.3 \%)$ \\
\hline Ceftriaxone & $36(53.8 \%)$ & $8(11.9 \%)$ & $23(34.3 \%)$ \\
\hline Cefotaxime & $39(58.2 \%)$ & $11(16.4 \%)$ & $17(25.4 \%)$ \\
\hline Piperacillin & $48(71.6 \%)$ & $9(13.4 \%)$ & $10(15 \%)$ \\
\hline Meropenem & $51(76.1 \%)$ & $3(4.5 \%)$ & $13(19.4 \%)$ \\
\hline
\end{tabular}

Table 3: Resistance and sensitivity of $E$. coli.

\begin{tabular}{|llll|}
\hline Antibiotics & Sensitive & Intermediate & Resistant \\
\hline Amoxicillin & $21(17.8 \%)$ & $34(28.8 \%)$ & $63(53.4 \%)$ \\
\hline Ampicillin & $18(15.3 \%)$ & $29(24.6 \%)$ & $71(60.1 \%)$ \\
\hline $\begin{array}{l}\text { Amoxicillin- } \\
\text { clavulanicacid }\end{array}$ & $30(25.4 \%)$ & $36(30.5 \%)$ & $52(44.1 \%)$ \\
\hline Ciprofloxacin & $69(58.5 \%)$ & $26(22 \%)$ & $23(19.5 \%)$ \\
\hline Norfloxacin & $73(61.9 \%)$ & $21(17.8 \%)$ & $24(20.3 \%)$ \\
\hline Gentamicin & $58(49.2 \%)$ & $19(16.1 \%)$ & $41(34.7 \%)$ \\
\hline Amikacin & $61(51.7 \%)$ & $23(19.5 \%)$ & $34(28.8 \%)$ \\
\hline Erythromycin & $71(60.2 \%)$ & $19(16.1 \%)$ & $28(23.7 \%)$ \\
\hline Nalidixic acid & $38(32.2 \%)$ & $17(14.4 \%)$ & $63(53.4 \%)$ \\
\hline Nitrofurantoin & $60(50.8 \%)$ & $22(18.6 \%)$ & $36(30.6 \%)$ \\
\hline Cotrimoxazole & $51(43.2 \%)$ & $11(9.3 \%)$ & $56(47.5 \%)$ \\
\hline Ceftriaxone & $48(40.7 \%)$ & $26(22 \%)$ & $44(37.3 \%)$ \\
\hline Cefotaxime & $53(45 \%)$ & $19(16.1 \%)$ & $46(38.9 \%)$ \\
\hline Piperacillin & $82(69.5 \%)$ & $14(11.9 \%)$ & $22(18.6 \%)$ \\
\hline Meropenem & $90(76.3 \%)$ & $11(9.3 \%)$ & $17(14.4 \%)$ \\
\hline Imipenem & $81(68.6 \%)$ & $18(15.3 \%)$ & $19(16.1 \%)$ \\
\hline
\end{tabular}

In this study, Pseudomonas aeruginosa isolates were found to be highly resistant to first line antibiotics, followed by Klebsiella pneumoniae and Escherichia coli. The Gram-positive isolates were having better susceptibility to Amikacin, Cephalosporins and Ciprofloxacin; but were more resistant to Ampicillin and Gentamicin in the present study. 
Table 4: Resistance and sensitivity of Klebsiella.

\begin{tabular}{|llll|}
\hline Antibiotics & Sensitive & Intermediate & Resistant \\
\hline Ciprofloxacin & $31(67.4 \%)$ & $7(15.2 \%)$ & $8(17.4 \%)$ \\
\hline Ofloxacin & $30(65.2 \%)$ & $6(13 \%)$ & $10(21.8 \%)$ \\
\hline Amoxicillin & $7(15.2 \%)$ & $14(30.4 \%)$ & $25(54.4 \%)$ \\
\hline Ampicillin & $12(26.1 \%)$ & $9(19.6 \%)$ & $25(54.3 \%)$ \\
\hline $\begin{array}{l}\text { Amoxicillin- } \\
\text { clavulanicacid }\end{array}$ & $6(13 \%)$ & $16(34.8 \%)$ & $24(52.2 \%)$ \\
\hline Gentamicin & $24(52.2 \%)$ & $11(23.9 \%)$ & $11(23.9 \%)$ \\
\hline Amikacin & $28(60.8 \%)$ & $8(17.4 \%)$ & $10(21.8 \%)$ \\
\hline Erythromycin & $24(52.2 \%)$ & $9(19.6 \%)$ & $13(28.2 \%)$ \\
\hline Cotrimoxazole & $16(34.8 \%)$ & $7(15.2 \%)$ & $23(50 \%)$ \\
\hline Ceftriaxone & $24(52.2 \%)$ & $7(15.2 \%)$ & $15(32.6 \%)$ \\
\hline Cefotaxime & $24(52.2 \%)$ & $6(13 \%)$ & $16(34.8 \%)$ \\
\hline
\end{tabular}

Table 5: Resistance and sensitivity of Pseudomonas.

\begin{tabular}{|llll|}
\hline Antibiotics & Sensitive & Intermediate & Resistant \\
\hline Ciprofloxacin & $8(33.3 \%)$ & $2(8.3 \%)$ & $14(58.3 \%)$ \\
\hline Gentamicin & $6(25 \%)$ & $3(12.5 \%)$ & $15(62.5 \%)$ \\
\hline Amikacin & $12(50 \%)$ & $4(16.7 \%)$ & $8(33.3 \%)$ \\
\hline Ceftriaxone & $5(20.8 \%)$ & $2(8.3 \%)$ & $17(70.8 \%)$ \\
\hline Cefotaxime & $7(29.2 \%)$ & $5(20.8 \%)$ & $12(50 \%)$ \\
\hline Piperacillin & $13(54.2 \%)$ & $1(4.2 \%)$ & $10(41.6 \%)$ \\
\hline Meropenem & $17(70.8 \%)$ & $3(12.5 \%)$ & $4(16.7 \%)$ \\
\hline Imipenem & $15(62.5 \%)$ & $4(16.7 \%)$ & $5(20.8 \%)$ \\
\hline
\end{tabular}

\section{DISCUSSION}

The antibiotic sensitivity pattern of organisms changes rapidly over a short period. It is especially true for developing countries where antibiotics are prescribed irrationally not only by the medical practitioners but the antibiotics are also purchased directly from the chemists without prescription. Reliable statistics on antibiotic resistance that are mandatory to control spread of resistant pathogens are available from the developed nations. These data are generated by large surveillance studies in countries such as the USA, Europe, Australia However such data are sparse in developing countries like India due to the lack of large scale studies. Hospital antibiograms are commonly used to help guide empiric antimicrobial therapy and are an important component of detecting and monitoring trends in antimicrobial resistance. According to Louie et al staphylococci were identified by standard methods including the gram stain, catalase test and tube coagulase test. ${ }^{13}$

In contrast to the results of our study where gram negative organisms are more predominant, in developed countries Gram positive bacteria are more commonly reported. This was in concordance with Aletayeb $\mathrm{SMH}$ et al, and Sundaram V et al. ${ }^{14,15}$ The present study shows increased resistance to Ampicillin, Amoxicillin, Cotrimoxazole and Ceftriaxone, these findings are in agreement with the increasing prevalence of resistance to these antimicrobial agents demonstrated by Egyptian, regional, and world- wide studies. ${ }^{16,17}$ The increased resistance to Pseudomonas could be due to increased use of antibiotics. ${ }^{18,19} \mathrm{~S}$. aureus, E. coli and Pseudomonas are the major pathogens in the present study similar to studies from other parts of India and worldwide. ${ }^{20-22}$

The bacteriological profile for causative organisms differs significantly between developed and developing countries. ${ }^{23,24}$ Klebsiella pneumoniae is the most common bacterial agent causing sepsis in developing countries, while Streptococcus and staphylococci are the common agents in developed countries. ${ }^{25-27}$ Even among developing countries, regional variation in prevalence of the bacterial agents causing infections exists. ${ }^{28,29}$

The overall improvement in the survival rate due to newer drugs, better care and advanced life support facilities has led to a change in the spectrum of agents causing sepsis in developed countries. However, there is a paucity of data on the recent trends of organisms causing sepsis in developing countries. Indian studies over the last three decades have reported high incidence of gram negative organisms among culture positive cases ${ }^{30-33}$ Klebsiella and other Gram-negative organisms were the common causes of infection in the present study as well other studies from India and Nigeria. Hence there is importance to prevent infection by Klebsiella pneumoniae. Amikacin should be used along with third generation cephalosporins for empirical treatment of gram negative sepsis.

In a study from North India, 30-80\% of the Gram negative isolates were resistant to third generation cephalosporins. Frequent local treatment during repetitive infections also causes the spread of resistant strains from hospital to patients and vice versa. ${ }^{34}$ The occurrence of P.aeruginosa as the predominant offending organism could be attributed to its minimum nutritional requirements and its relative resistance to antibiotics. ${ }^{35}$ In the present study, prevalence of Staphyloccus aureus (16.7\%) is similar to that reported from Nagpur $(19.56 \%)$ and Vellore $(24 \%)$ in India. ${ }^{36,37}$ Finding of more concern is the resistance of positive isolates to piperacillin-tazobactam (beta lactam-beta lactamase inhibitor) combination since they are the antibiotics of choice in the treatment of infection due to resistant bacteria or the carbapenems. ${ }^{38}$

A first line antibiotic treatment should be primarily directed against the pathogen. For coverage of gram negative bacteria, beta lactam-betalactamase inhibitor combinations would be more useful. Use of mono drug therapy with cephalosporins, aminoglycosides and fluoroquinolones need to be guided by the sensitivity report. Lastly, continued monitoring of susceptibility pattern need to be carried out in individual settings so as to detect the true burden of antibiotic resistance in organisms and prevent their further emergence by judicious use of drugs.

In most clinical situations, there is a need to initiate empirical antimicrobial therapy before obtaining the 
microbial results. However, the situation is further complicated by the emergence of MDR pathogens. Obviously, there is a great need for obtaining data on prevalent strains; along with the susceptibility pattern, to help in revising antibiotic policy and guiding clinicians for the better management of patients; particularly in developing countries. This "local" pattern of predominance should be taken into consideration upon prescribing antimicrobials in this locality. Obviously, this "local" difference explains the changing pattern of causative pathogens over time, even at the same hospital. Fortunately, this higher prevalence was closely related to the susceptibility pattern. This confirms the importance of implementing continued local surveillance programmes.

Present findings together with previous ones are suggestive of need of periodic monitoring of antibiotic sensitivity pattern of the bacterial isolates to provide effective treatment and prevent the emergence of resistance among commonly used antimicrobial agents particularly in developing countries like ours. If the antibiotic according to the sensitivity pattern is administered to these patients at an early stage of the disease, morbidity and mortality due to microorganisms can be minimized. This can be tackled by multicentre large scale studies of antibiotic sensitivity pattern, to generate nationwide or more appropriately region-specific antibiograms.

\section{Funding: No funding sources}

Conflict of interest: None declared

Ethical approval: The study was approved by the Institutional Ethics Committee

\section{REFERENCES}

1. Alpuche C, Garau J, and Lim V. Global and local variations in antimicrobial susceptibilities and resistance development in the major respiratory pathogens. Int J Antimicrob Agents. 2007;30(2):1358.

2. Pfaller MA, Jones RN, Doren GV, Kugler K, The SENTRY Participants Group. Bacterial Pathogens Isolated from Patients with Bloodstream Infection: Frequencies of Occurrence and Antimicrobial Susceptibility Patterns from the SENTRY Antimicrobial Surveillance Program (United States and Canada, 1997). Antimicrob Agents Chemother 1998;42:1762-70. (PMid: 9661018 PMCid: PMC105680).

3. Global Initiative for Chronic Obstructive Lung Disease. Global Strategy for the Diagnosis and Prevention of Chronic Obstructive Pulmonary Disease. Updated; 2009.

4. Mandell LA, Wunderink RG, Anzueto A, Bartlett JG, Campbell GD, Dean NC, et al. Infectious Diseases Society of America/American Thoracic Society Consensus Guidelines on the Management of Community-Acquired Pneumonia in Adults. Clin Infect Dis. 2007;44(2):S27-72. (PMid:17278083).
5. Garc1'a-Rey C, Aguilar L, Baquero F, Casal J, Dal-Ré $\mathrm{R}$. Importance of Local Variations in Antibiotic Consumption and Geographical Differences of Erythromycin and Penicillin Resistance in Streptococcus pneumoniae. J Clin Microbiol. 2002;40:159-64. (PMCid:PMC120130).

6. Lakshmi V. Need for national/regional guidelines and policies in India to combat antibiotic resistance. Indian J of Med Microbiol. 2008;26:105-7.

7. Kulpati DDS, Kumar A. Flexible fibreoptic bronchoscopy in lower respiratory tract infections. Ind J Chest Dis Allied Sci. 1980;22:39-46.

8. Kulpati DDS, Khastgir T. Reappraisal of pneumonias. JAPI. 1988;36(ii);660-64.

9. Sharma BK, Manjunatha S, Varma S. Profile of pneumonias in hospitalized medical patients. Ind J Chest Dis Allied Sci. 1988;30:199-204.

10. Barlett JG. Bacteriological diagnosis of pulmonary infections. In Sackner MA (Ed:) Diagnostic techniques in pulmonary disease, part 1 New York, Marcel Dekker Inc.; 1980:707-745.

11. Wollschlager C, Khan F. The contribution of blood cultures to the diagnosis and management of community acquired pneumonia. Am Rev Resp Dis. 1985;131:80.

12. Mackie TJ, McCartney JE. Practical medical microbiology. 14 $4^{\text {th }}$ Ed. New York: Churchill Livingstone; 1996.

13. Louie L, Goodfellow J, Mathieu P, Glatt A, Louie M, Simor AE. Rapid detection of methicillin-resistant staphylococci from blood culture bottles by using a multiplex PCR assay. J Clin Microbiol. 2002;40:278690.

14. Sundaram V, Kumar P, Dutta S, Mukhopadhay K, Ray $\mathrm{P}$, Gautam V, et al. Blood culture confirmed bacterial sepsis in neonates in a North Indian tertiary care center: Changes over the last decade. Jpn J Infect Dis. 2009;62:46-50.

15. Mathur M, Shah H, Dixit K, Khambadkone S, Chakrapni A, Irani S. Bacteriological profile of neonatal septicemic cases (for the year 1990-91) J. Post Grad. Med. 1994;40(1):18-20.

16. Wasfy MO, Pimentel G, Abdel-Maksoud M, Russell $\mathrm{KL}$, Barrozo CP, Klena JD, et al. Antimicrobial susceptibility and serotype distribution of Streptococcus pneumoniae causing meningitis in Egypt, 1998-2003. J Antimicrob Chemother. 2005;55:958-64. (PMid:15820983).

17. Borg MA, Tiemersma E, Scicluna E, van de SandeBruinsma N, de Kraker M, Monen J, et al. Prevalence of penicillin and erythromycin resistance among invasive Streptococcus pneumoniae isolates reported by laboratories in the southern and eastern Mediterranean region. Clin Microbiol Infect. 2009;15:232-7.

18. Mathur M, Shah H, Dixit K, Khambadkone S, Chakrapni A, Irani S. Bacteriological profile of neonatal septicemic cases (for the year 1990-91) J. Post Grad Med. 1994;40(1):18-20. 
19. Palikhe N. Prescribing pattern of antibiotics in pediatric hospital of Kathmandu Valley. Kathmandu Univ Med J. 2004;2:6-12.

20. Zargar AH, Masoodi SR, Laway BA, Wani AI, Bashir MI. Ciprofloxacin in the management of soft tissue infections in diabetes mellitus. J Assoc Phys India. 2000;48:757-8.

21. Sader HS, Jones RN, Silva JB. Skin and soft tissue infections in Latin American medical centers: fouryear assessment of the pathogen frequency and antimicrobial susceptibility patterns. Diagn Microbiol Infect Dis. 2002;44:281-8.

22. Rennie RP, Jones RN, Mutnick AH, and the SENTRY Program Study Group (North America). Occurrence and antimicrobial susceptibility patterns of pathogens isolated from skin and soft tissue infections: report from the SENTRY Antimicrobial Surveillance Program (United States and Canada, 2000) Diagn Microbiol Infect Dis. 2003;45:287-93.

23. Sanghvi KP, Tudehope DI. Neonatal bacterial sepsis in a neonatal intensive care unit: a 5 year analysis. $\mathbf{J}$ Paediatr Child Health. 1996;32:333-8.

24. Stoll BJ, Hansen N, Fanaroff AA, Wright LL, Carlo WA, Ehrenkranz RA, et al. Changes in pathogens causing early-onset sepsis in very-low-birth-weight infants. N Engl J Med. 2002;347:240-7.

25. Kaistha N, Mehta M, Singla N, Garg R, Chander J. Neonatal septicemia isolates and resistance patterns in a tertiary care hospital of North India. J Infect Dev Ctries. 2009;4:55-7.

26. Anderson-Berry AL, Bellig LL, Ohning BL. Neonatal sepsis. emedicine Pediatrics: Cardiac Disease and Critical Care Medicine 2010;978352. (Updated 2010 Feb 23; Cited 2010 Sep 22).

27. Iregbu KC, Elegba OY, Babaniyi IB. Bacteriological profile of neonatal septicaemia in a tertiary hospital in Nigeria. Afr Health Sci. 2006;6:151-4.

28. Kuruvilla KA, Pillai S, Jesudason M, Jana AK. Bacterial profile of sepsis in a neonatal unit in south India. Indian Pediatr. 1998;35:851-8.

29. Chacko B, Sohi I. Early onset neonatal sepsis. Indian J Pediatr. 2005;72:23-6.

30. Ailani RK, Agastya G, Ailani R, Mukunda BN, Shekar $\mathrm{R}$. Doxycycline is a cost - effective therapy for hospitalized patients with community - acquired pneumonia. Arch Intern Med. 1999;159:266-70.

31. Almirall J, Morato I, Riera F, Verdaguer A, Priu R, Coll $\mathrm{P}$, et al. Incidence of community-acquired pneumonia and Chlamydia pneumoniae infection: a prospective multicentre study. Eur Respr J. 1993 Jan $1 ; 6(1): 14-8$

32. Amsden GW. Pneumococcal Macrolide resistance: myth or reality? J Antimicrob Chemother. 1999;44:16.

33. Berntsson E, Lagergard T, Strannegard O, Trollfors B. Etiology of community- acquired pneumonia in out patients. Eur J Clin Microbiol. 1986;5:446-7.

34. Park DC, Lee SK, Cha CI, Lee SO, Lee MS, Yeo SG. Antimicrobial resistance of Staphylococcus from otorrhea in chronic suppurative otitis media and comparison with results of all isolated Staphylococci. Eur J Clin Microbiol Infecti Dis. 2008 Jul 1;27(7):571.

35. Pollock M. Special role pseudomonas aeruginosa in CSOM: Workshop on CSOM etiology and management. An Otorhinolaryng. 1996;17(6).

36. Tahnkiwale SS, Roy S, Jalgaonkar SV. Methicillins resistance among isolates of Staphylococcus aureus: antibiotic sensitivity pattern and phage typing. Ind $\mathbf{J}$ Med Sci. 2002;56:330-4.

37. Pulimood TB, Lalitha MK, Jesdason MV, Pandian R, Selwyn J, John TJ. The spectrum of antimicrobial resistance among Methicillin resistant Staphylococcus aureus (MRSA) in a tertiary care centre in India. Indian J Med Res. 1996;103:212-5.

38. Pitout JDD, Sanders CC, Sanders WE Jr. Antimicrobial resistance with focus on $\beta$-lactam resistance in Gram negative bacilli. Am J Med. 1997;103:51-9.

Cite this article as: Brethis CS, Mahender G, Thamizharasan S, Kumar SK, Sudharson T. Antibiotic sensitivity profile and resistance of microorganisms isolated from south Indian population, a hospital based study at Velappanchavady, Chennai, India. Int J Basic Clin Pharmacol 2019;8:869-74. 